\title{
Water-Induced Dimensionality Reduction in Metal-Halide Perovskites
}

Bekir Turedi, Kwangjae Lee, Ibrahim Dursun, Badriah Alamer, Zhennan Wu, Erkki Alarousu, Omar F. Mohammed, Namchul Cho, and Osman M. Bakr

J. Phys. Chem. C, Just Accepted Manuscript • DOI: 10.1021/acs.jpcc.8b01343 • Publication Date (Web): 30 Mar 2018

Downloaded from http://pubs.acs.org on April 9, 2018

\section{Just Accepted}

"Just Accepted" manuscripts have been peer-reviewed and accepted for publication. They are posted online prior to technical editing, formatting for publication and author proofing. The American Chemical Society provides "Just Accepted" as a service to the research community to expedite the dissemination of scientific material as soon as possible after acceptance. "Just Accepted" manuscripts appear in full in PDF format accompanied by an HTML abstract. "Just Accepted" manuscripts have been fully peer reviewed, but should not be considered the official version of record. They are citable by the Digital Object Identifier (DOI®). "Just Accepted" is an optional service offered to authors. Therefore, the "Just Accepted" Web site may not include all articles that will be published in the journal. After a manuscript is technically edited and formatted, it will be removed from the "Just Accepted" Web site and published as an ASAP article. Note that technical editing may introduce minor changes to the manuscript text and/or graphics which could affect content, and all legal disclaimers and ethical guidelines that apply to the journal pertain. ACS cannot be held responsible for errors or consequences arising from the use of information contained in these "Just Accepted" manuscripts. 


\section{Water-Induced Dimensionality Reduction in Metal-}

\section{Halide Perovskites}

Bekir Turedi, ${ }^{1,2}$ Kwang Jae Lee, ${ }^{1,2}$ Ibrahim Dursun, ${ }^{1,2}$ Badriah Alamer, ${ }^{1,2}$ Zhennan Wu, ${ }^{1,2}$ Erkki

Alarousu, ${ }^{1,3}$ Omar F. Mohammed, ${ }^{1,3}$ Namchul Cho ${ }^{4, *}$ and Osman M. Bakr ${ }^{1,2, *}$

${ }^{1}$ Division of Physical Sciences and Engineering, King Abdullah University of Science and Technology (KAUST), Thuwal 23955-6900, Kingdom of Saudi Arabia

${ }^{2}$ Kaust Catalyst Center (KCC), King Abdullah University of Science and Technology (KAUST), Thuwal 23955-6900, Kingdom of Saudi Arabia

${ }^{3}$ Kaust Solar Center (KSC), King Abdullah University of Science and Technology (KAUST), Thuwal 23955-6900, Kingdom of Saudi Arabia

${ }^{4}$ Department of Energy Systems, Soonchunhyang University, Asan 31538, Republic of Korea

*Email: chon7@sch.ac.kr, osman.bakr@,kaust.edu.sa

ABSTRACT: Metal-halide perovskite materials are highly attractive materials for optoelectronic applications. However, the instability of perovskite materials caused by moisture and heatinduced degradation impairs future prospects of using these materials. Here we employ water to directly transform films of the three-dimensional (3D) perovskite $\mathrm{CsPbBr}_{3}$ to stable twodimensional (2D) perovskite-related $\mathrm{CsPb}_{2} \mathrm{Br}_{5}$. A sequential dissolution-recrystallization process governs this water induced transformation under $\mathrm{PbBr}_{2}$ rich condition. We find that these postsynthesized 2D perovskite-related material films exhibit excellent stability against humidity and high photoluminescence quantum yield. We believe that our results provide a new synthetic method to generate stable 2D perovskite-related materials that could be applicable for light emitting device applications. 


\section{Introduction}

Organic-inorganic hybrid perovskites are attractive semiconducting materials because of their extraordinary electrical and optical properties that have been studied intensively in the field of photovoltaics, ${ }^{1-7}$ electroluminescence, ${ }^{8-9}$ optical pumping, ${ }^{10}$ photodetectors, ${ }^{11-17}$ and field-effect $\operatorname{transistors}^{18-19}$, energy storage $^{20}$. The fundamental properties of perovskite materials are determined mainly by band energy engineering, film morphology, crystallinity, defects, dimensionality and surface properties..$^{21-30}$ By virtue of extensive materials and device engineering over the last few years, significant progress has been made in perovskite-based optoelectronic devices. In particular, hybrid perovskites are highly attractive for use in light emitting diodes (LEDs) owing to their high color purity, photoluminescence quantum yield (PLQY), external quantum efficiency (EQE), and tunable band gap.

Low-dimensional perovskite and its derivatives are promising materials for light-emitting applications. Compared to their 3D counterpart, charge carriers in low-dimensional perovskite derivatives are confined to the extremely narrow active layers isolated dielectrically from one another by a long organic spacer. This layered or isolated nature of the compounds gives rise to the large exciton binding energies and quantum confinement, promoting fast radiative carrier recombination which is favorable for efficient light-emitting applications. However, breaking up the 3D metal-halide perovskite network into 2D sheets, 1D rods, and 0D isolated clusters using long alkyl (or aryl) ammonium ligands makes them chemically vulnerable because ammonium cations are intrinsically unstable against moisture. Deprotonation of the alkylammonium in water initiates the degradation process of the hybrid perovskites. ${ }^{31-32}$ Moreover, theoretical calculations 
without considering solvents and oxygen effects suggest that hybrid perovskite materials are intrinsically unstable because of their low Madelung electrostatic potential. ${ }^{32-33}$ Therefore, compared with alkyl ammonium cation based perovskites, all inorganic perovskites such as cesium lead halide $\left(\mathrm{CsPbX}_{3}\right)$ exhibit improved stability against moisture. ${ }^{34-35}$ Although $\mathrm{CsPbX}$ perovskites have better moisture stability than hybrid perovskites, the strong ionic nature of cesium lead halide perovskites still gives rise to chemical instability against polar solvents like water. ${ }^{36}$ Therefore, the moisture-induced instability is still a ubiquitous impediment for most perovskite materials regardless of the nature of cations or halides.

Here we demonstrate that introducing water on 3D cesium lead bromide $\left(\mathrm{CsPbr}_{3}\right)$ films leads to a direct transformation to highly emissive and thermally stable $2 \mathrm{D} \mathrm{CsPb}{ }_{2} \mathrm{Br}_{5}$ perovskiterelated material (PRM) films. The water-induced transformation is governed by a sequential dissolution-recrystallization process under $\mathrm{PbBr}_{2}$ rich conditions. We find that the postsynthesized 2D PRM films exhibit excellent stability against humidity and high photoluminescence quantum yield up to $29.6 \%$ in solid films. Surprisingly, the 2D PRM films show excellent thermal stability as well and do not lose their strong emission even after annealing at $80{ }^{\circ} \mathrm{C}$ for 24 hours in air at $65 \%$ relative humidity (RH). Our new transformation method provides a robust strategy for generating 2D PRM films without utilizing any alkylammonium cations or ligands as well as rationally tuning optical properties.

\section{Methods}

Reagents. Cesium (I) Acetate (CsoAc, Sigma Aldrich), and lead (II) bromide ( $\mathrm{PbBr}_{2}$, Sigma Aldrich), and lead (II) chloride ( $\mathrm{PbCl}_{2}$, Sigma Aldrich) were used as received without further purification. 
Preparation of $\mathrm{CsPbBr}_{3}$ and $\mathrm{CsPb}_{2} \mathrm{Br}_{5}$ films. The precursor solution was prepared by dissolving $1 \mathrm{M} \mathrm{CsoAc}$ and $2 \mathrm{M} \mathrm{PbBr}_{2}$ in DMSO separately. The solutions were heated until they are fully dissolved. $0.5 \mathrm{ml}$ of each CsoAc and $\mathrm{PbBr}_{2}$ solutions and $0.5 \mathrm{ml}$ of DMF was mixed and used for film preparation. Before film deposition, all glass substrates were cleaned in acetone and isopropanol for $10 \mathrm{~min}$ by sonication. The substrates were oxygen-plasma cleaned for $3 \mathrm{~min}$ to obtain required hydrophilicity for the uniform spread of drop-casted solution over the substrate. The $\mathrm{CsPbBr}_{3}$ perovskite films were prepared by simple drop-casting of $80 \mu$ of precursor solution on the glass substrates while heating the substrates at $80{ }^{\circ} \mathrm{C}$, and the substrates were annealed at the same temperature for $10 \mathrm{~min}$. Different water treatment processes were applied to the $\mathrm{CsPbBr}_{3}$ films to convert them more emissive $\mathrm{CsPb}_{2} \mathrm{Br}_{5}$ phase. Simple dropcasting of water or water vapor was employed on top of the perovskite films for transformation. To make more uniform film we left the film in a humidity chamber with $90 \%$ relative humidity (RH) and waited until the $\mathrm{CsPBBr}_{3}$ converts completely to $\mathrm{CsPb}_{2} \mathrm{Br}_{5}$. The same procedures were performed for fabrication of $\mathrm{CsPb}_{2} \mathrm{Br}_{5(1-\mathrm{x})} \mathrm{Cl}_{5 \mathrm{x}}$ films.

Characterization. Temperature-dependent (TD) and ambient X-ray diffraction (XRD): The powder X-ray diffraction pattern was collected using Bruker AXS D8 diffractometer.

Photoluminescence (PL), photoluminescence quantum yield (PLQY): The steady-state PL and PLQY were analyzed using Edinburgh Instruments FLS920 Spectrophotometer with an integrated sphere by excitation at $440 \mathrm{~nm}$ wavelength. The PLQY, defined as the percentage of photons emitted over photons absorbed by the sample, was determined by using an integrating sphere. A direct and an indirect measurement were performed to measure PLQY accurately. The re-excitation of the sample from excitation light reflected within the sphere was removed to get accurate results. ${ }^{37}$ 
Time-resolved photoluminescence (TRPL) and Temperature-dependent PL (TDPL): Timeresolved photoluminescence was performed using an Ultrafast Systems HALCYONE fluorescence spectrometer with $490 \mathrm{~nm}$ excitation wavelength. The temperature-dependent photoluminescence was measured using a Horiba JY LabRAM Aramis spectrometer with an Olympus 50x lens in a Linkam THMS600 stage. A $473 \mathrm{~nm}$ laser was used as the excitation source.

Fourier-Transform Infra-Red Spectroscopy (FT-IR): FT-IR measurement was carried out using Thermo Scientific Nicolet 6700 FT-IR spectrometer.

The steady-state Absorption: The steady-state reflection spectra were recorded using Edinburgh Instruments FLS920 Spectrophotometer with an integrating sphere. Then Kubelka-Munk ${ }^{6,38}$ relation was utilized to convert the reflectance spectra to absorption spectra.

Scanning electron microscopy (SEM): A Quanta 200 FEG instrument was used to obtain SEM images.

Transmission electron microscopy (TEM): TEM analysis was carried out with a Titan TEM (FEI Company) operating at a beam energy of $300 \mathrm{keV}$ and equipped with a Tridiem postcolumn energy filter (Gatan, IQD.). The powder of $\mathrm{CsPb}_{2} \mathrm{Br}_{5}$ is scratched from film and dispersed in toluene to prepare the TEM sample.

\section{Results and discussion}

\section{Direct transformation of 3D $\mathrm{CsPbBr}_{3}$ films to 2D $\mathrm{CsPb}_{2} \mathrm{Br}_{5}$ by water treatment.}

We employed water to produce stable $\mathrm{CsPb}_{2} \mathrm{Br}_{5}$ films from $\mathrm{CsPbBr}_{3}$. Figure 1a illustrates a simple water treatment process. Water dropped directly on the $\mathrm{CsPBr}_{3}$ film, and then the film 
was annealed at $100{ }^{\circ} \mathrm{C}$ for $5 \mathrm{~min}$ to dry water. Figure $1 \mathrm{~b}$ shows water treated films under room light and UV (365 nm) irradiation. The white color area under room light emits green light under UV irradiation. In addition to the direct water dropping method, we also used water vapor using the humidity chamber $(90 \% \mathrm{RH}, \mathrm{RT})$ and observed that the $\mathrm{Cs}_{\mathrm{PbBr}}$ films become emissive. We find that the resulting emissive product is $\mathrm{CsPb}_{2} \mathrm{Br}_{5}$ as examined below.

The $\mathrm{CsPbBr}_{3}$ films were fabricated by drop casting of CsoAc: $\mathrm{PbBr}_{2}(1: 2)$ in DMF:DMSO (1:2) solution on glass substrates and annealed at $80^{\circ} \mathrm{C}$ for $10 \mathrm{~min}$ in air. As illustrated in Figure 1c, $\mathrm{CsPbBr} 3$ has a simple cubic structure with corner sharing $\mathrm{PbBr}_{6}{ }^{4-}$ octahedra. In contrast, the transformed tetragonal $\mathrm{CsPb}_{2} \mathrm{Br}_{5}$ has a unique sandwiched structure with alternating $\left(\mathrm{Pb}_{2} \mathrm{Br}_{5}\right)^{-}$ and $\mathrm{Cs}^{+}$layers.

The water-induced transformation can take place with a two-step process under $\mathrm{PbBr}_{2}$ rich condition. As an initial step, water accelerates the removal of $\mathrm{Cs}^{+}$ions from $\mathrm{CsPbBr}_{3}$, which causes the irreversible decomposition of perovskites generating $\mathrm{PbBr}_{2}, \mathrm{Cs}^{+}(\mathrm{aq})$ and $\mathrm{Br}^{-}(\mathrm{aq})$. This is because of the high solubility of $\mathrm{CsBr}$ in water and strong ionic nature of $\mathrm{CsPbBr}_{3}$. In a $\mathrm{PbBr}_{2}$ rich condition such as 1:2 molar ratio of CsoAc and $\mathrm{PbBr}_{2}$, tetragonal $\mathrm{CsPb}_{2} \mathrm{Br}_{5}$ can be obtained by the recrystallization process in water through the anisotropic growth of $2 \mathrm{D} \mathrm{CsPb}_{2} \mathrm{Br}_{5}$ which is a thermodynamically favorable state at given stoichiometric ratio with the existence of water. Since water can dissolve $\mathrm{CsPbBr}_{3}$ immediately, this transition is completed nearly within $1 \mathrm{~min}$ after all water molecules are evaporated by thermal annealing (See video in supporting information). Evaporation of water molecules was monitored by measuring infrared spectroscopy of the samples before and after water treatment and thermal annealing. As shown in Figure 2, the broad $\mathrm{OH}$ stretching vibration of water molecule around $3300 \mathrm{~cm}^{-1}$ is disappeared after thermal annealing at $100{ }^{\circ} \mathrm{C}$ for $5 \mathrm{~min}$. 
Next, we examined how stoichiometry affects the crystal structure. With 1:1 and 2:1 molar ratios of $\mathrm{CsoAc}: \mathrm{PbBr}_{2}$, we were not able to observe strong green emission after water treatment because of inefficient phase transformations with stoichiometric imbalance (Figure S1). The highest transformation level into $\mathrm{CsPb}_{2} \mathrm{Br}_{5}$ was achieved with a 1:2 ratio according to the XRD peak intensity at $11.6^{\circ}$ (almost 2.5 times that of materials synthesized with a 1:1 ratio and much higher than those using a 2:1 ratio) (Figure S1c), which corresponds to the (002) plane of the phase. This is in good agreement with previous reports on the formation of $\mathrm{CsPb}_{2} \mathrm{Br}_{5}$ with the excess of $\mathrm{PbBr}_{2}$ under thermal annealing, and further supported by the calculation of reaction probability with the Gibbs free energy of $\mathrm{CsPbBr}_{3}, \mathrm{PbBr}_{2}$, and $\mathrm{CsPb}_{2} \mathrm{Br}_{5} .{ }^{39}$

Figure $3 b$ shows the X-ray diffraction (XRD) patterns of the original $\mathrm{CsPbBr}_{3}$, transformed $\mathrm{CsPb}_{2} \mathrm{Br}_{5}$ by water treatment, and after thermal annealing at $80{ }^{\circ} \mathrm{C}$ for 24 hours. The XRD result clearly shows that the cubic $\mathrm{CsPbBr} 3$ are converted to the tetragonal $\mathrm{CsPb}_{2} \mathrm{Br}_{5}$ after water treatment. The (002) plane of the tetragonal $\mathrm{CsPb}_{2} \mathrm{Br}_{5}$ at $11.6^{\circ}$ shows domination over the remaining small peaks of $3 \mathrm{D} \mathrm{CsPbBr}$. Note that the transformed $\mathrm{CsPb}_{2} \mathrm{Br}_{5}$ films are highly stable, i.e., maintaining the tetragonal XRD pattern even after thermal annealing at $80{ }^{\circ} \mathrm{C}$ for 24 hours in the air. Also, the XRD after humidification of the film does not change after annealing (Figure S2), it shows the conversion occurs independent to heating. More interestingly, the strong green emission from the transformed $\mathrm{CsPb}_{2} \mathrm{Br}_{5}$ films is not quenched by thermal annealing in air for 24 hours (Figure 3a). These results clearly show that the transformed $\mathrm{CsPb}_{2} \mathrm{Br}_{5}$ films possess good thermal stability. We further examined its thermal stability by measuring XRD from $303 \mathrm{~K}$ to $583 \mathrm{~K}$ and found that there is a negligible change in XRD patterns up to $563 \mathrm{~K}$ (Figure S3). 
To get a deeper understanding of water induced transformation process, we performed a detailed analysis of absorption spectra under the phase transformation from $\mathrm{CsPbBr} 3$ to $\mathrm{CsPb}_{2} \mathrm{Br}_{5}$. Figure 4a shows the absorption spectra upon the exposure time of $\mathrm{CsPbr}_{3}$ films on water vapor generated from a humidifier. By water vapor treatment for 40 seconds, the absorption across the spectral range of 370-550 nm decreases immediately due to the dissolution (or decomposition) of $\mathrm{CsPbBr}_{3}$. At 40 seconds, a new peak at $370 \mathrm{~nm}$ was emerged and become more and more distinct by further water vapor treatment. In the range of 150-220 seconds, another absorption peak around $390 \mathrm{~nm}$ was generated and disappeared after 220 seconds. We postulate that this peak could be assigned to $\left(\mathrm{Pb}_{2} \mathrm{Br}_{5}\right)^{-}$intermediates. For structural investigation, scanning electron microscopy (SEM) and high resolution transmission electron microscopy (HRTEM) were used. The transformed $\mathrm{CsPb}_{2} \mathrm{Br}_{5}$ film's morphology could be seen in the SEM micrograph in Figure S4a. The HRTEM images in Figures S4b and c reveal interplanar distances of about $0.42 \mathrm{~nm}$ and $0.38 \mathrm{~nm}$, which could be assigned to the (020) and (004) planes, respectively. The HRTEM results are in good match with the XRD results. Figure $4 \mathrm{~b}$ clearly shows the difference of absorption spectra between $\mathrm{CsPbBr}_{3}$ and $\mathrm{CsPb}_{2} \mathrm{Br}_{5}$. The band gap of $3.35 \mathrm{eV}$ estimated from the absorption edge of $\mathrm{CsPb}_{2} \mathrm{Br}_{5}$ films is in good agreement with the previously reported values from $\mathrm{CsPb}_{2} \mathrm{Br}_{5}$ single crystals. ${ }^{40}$

Figure $4 \mathrm{c}$ shows the photoluminescence spectra of as-prepared $\mathrm{CsPbBr}$, transformed $\mathrm{CsPb}_{2} \mathrm{Br}_{5}$ and annealed $\mathrm{CsPb}_{2} \mathrm{Br}_{5}$ films. The PL emission spectra show that the maximum PL peaks at 527 $\mathrm{nm}$ for $\mathrm{CsPbBr}_{3}$ and $532 \mathrm{~nm}$ for both transformed and annealed $\mathrm{CsPb}_{2} \mathrm{Br}_{5}$ films. A high PLQY of 29.6\% was observed from the solid films of $\mathrm{CsPb}_{2} \mathrm{Br}_{5}$ with the excitation wavelength of $440 \mathrm{~nm}$ (Figure S5). This PLQY value is relatively higher than that of generally reported values from $\mathrm{CsPbBr}_{3}$ colloidal nanocrystals. The relatively high PLQY, especially in solid films, from the 
transformed $\mathrm{CsPb}_{2} \mathrm{Br}_{5}$ is because there is no aggregation induced PL quenching in solid state and loss of ligands by thermal annealing or oxidation with water. In addition, the time-resolved PL measurement was carried out on the transformed $\mathrm{CsPb}_{2} \mathrm{Br}_{5}$ films to characterize carrier recombination dynamics. The PL decay of $\mathrm{CsPb}_{2} \mathrm{Br}_{5}$ shows a single exponential decay profile with a lifetime of 50.4 ns (Figure 4d). By using PLQY and average lifetime with the basic equations $\left(k_{\mathrm{r}}=\Phi / \tau_{\text {ave. }}\right.$ and $k_{\mathrm{nr}}=(1-\Phi) / \tau_{\text {ave. }}$, where $\Phi$ is the PLQY, and $\tau_{\text {ave. }}$ is the average PL lifetime), we estimated the radiative $\left(k_{\mathrm{r}}\right)$ decay rate of $0.0059 \mathrm{~ns}^{-1}$ and nonradiative $\left(k_{\mathrm{nr}}\right)$ decay rates of $0.014 \mathrm{~ns}^{-1}$.

To get a better insight into the excitonic features of the transformed $\mathrm{CsPb}_{2} \mathrm{Br}_{5}$ films and correlate it with the PL properties, we measured TD-PL spectra of the $\mathrm{CsPb}_{2} \mathrm{Br}_{5}$ films (Figure 5a). The increase of temperature leads to the small blue shift of PL peaks from 532 to $527 \mathrm{~nm}$ and the decrease of PL intensity (Figure $5 \mathrm{~b}$ ) with increasing a full width at half maximum (FWHM) (Figure 5c). The blue shift of PL peaks can be interpreted with thermal expansion of the crystal lattice and the electron-phonon coupling. ${ }^{41-43}$ The spectral linewidth broadening with increasing temperature may arise from charge-carrier interactions with optical phonons during the carrier recombination process. ${ }^{41,44}$ To estimate the exciton binding energy of the transformed $\mathrm{CsPb}_{2} \mathrm{Br}_{5}$ films, the TD- PL intensity curve was fitted by using the equation: $I(T)=I_{0} /(1$ $\left.+A \exp \left(E_{\mathrm{b}} / k_{\mathrm{B}} T\right)\right)$, where $I_{0}$ is the estimated integrated PL intensity at $0{ }^{\circ} \mathrm{K}, k_{\mathrm{B}}$ is the Boltzmann constant, and $E_{\mathrm{b}}$ is the exciton binding energy. An $E_{\mathrm{b}}$ of $99.7 \pm 12.4 \mathrm{meV}$ was estimated for $\mathrm{CsPb}_{2} \mathrm{Br}_{5}$ films, which is higher than that of previously reported values for $\mathrm{CsPbBr}_{3}(30 \sim 50$ $\mathrm{meV}) .{ }^{45-46}$ This high exciton binding energy reveals that the spatially distinguished electronic states of the transformed $\mathrm{CsPb}_{2} \mathrm{Br}_{5}$ play a significant role in the absorption and emission process. 
In addition to the $\mathrm{CsPb}_{2} \mathrm{Br}_{5}$, we also examined the structural evolution of the other halide composition of $\mathrm{CsPb}_{2} \mathrm{Br}_{5(1-\mathrm{x})} \mathrm{Cl}_{5 \mathrm{x}}$. Optical emission spectra of layered structure can be tuned from green to blue (Figure 6a) by adjusting the ratio of chloride to bromide. The PL peak position was blue shifted to $473 \mathrm{~nm}$ for $\mathrm{x}=0.37$. The XRD patterns with different ratios of chloride (Figure $6 \mathrm{~b}$ ) show that the layered structure is mostly maintained in the tetragonal phase. As expected, upon incorporation of $\mathrm{Cl}^{-}$the XRD peak for (002) plane (Figure S6) shifts to higher $2 \theta$ angles by shrinkage of the lattice constant.

Overall, we demonstrated that water-induced dimensionality transformation could be a powerful strategy for generating emissive 2D PRMs. However, care must be taken before generalizing our results because the origin of the green emission from the $\mathrm{CsPb}_{2} \mathrm{Br}_{5}$ is still obscure. Recent reports including from our group revealed that $\mathrm{CsPb}_{2} \mathrm{Br}_{5}$ single crystals ${ }^{40}$ and nanosheets $^{39}$ (in their ideal intrinsic forms) are PL inactive because they are indirect band gap materials. However, several reports are showing that $\mathrm{CsPb}_{2} \mathrm{Br}_{5}$ nanoplates have a strong green emission and also exhibit low-threshold amplified spontaneous emission. ${ }^{47-48}$ One plausible hypothesis is that small amounts of embedded $\mathrm{CsPbBr}_{3}$ crystals in $\mathrm{CsPb}_{2} \mathrm{Br}_{5}$ materials maybe the source of the green emission. However, our excitation wavelength-dependent emission intensity spectral maps reveal that the maximum PL comes from a clear excitation peak around $370 \mathrm{~nm}$, which is close band edge of $\mathrm{CsPb}_{2} \mathrm{Br}_{5}$ as shown in Figure $\mathrm{S} 7 \mathrm{~b}$. This means that the majority of green emission has a strong correlation with the transformed $\mathrm{CsPb}_{2} \mathrm{Br}_{5}$. Essentially, lattice strain typically exists in nano-scale materials, which could influence the band structure of indirect band gap materials. In addition, dissolution-recrystallization processes caused by water might initiate the formation of emissive centers which could be possibly generated by defects or surface states in PRMs. ${ }^{28-29,}{ }^{49-53}$ It is well known that surface defects can be easily generated by oxygen or 
moisture induced reorientation of crystal structure or decomposition. Indeed, we also observed that $\mathrm{PL}$ inactive $\mathrm{CsPb}_{2} \mathrm{Br}_{5}$ single crystals turn green photoluminescent after prolonged exposure to a humid atmosphere (Figure S8). Accordingly, for our transformed $\mathrm{CsPb}_{2} \mathrm{Br}_{5}$ films the presence of emissive centers such as the surface states and defects located inside the $\mathrm{CsPb}_{2} \mathrm{Br}_{5}$ crystals as well as at the surface generated by water treatment might be correlated with the emission properties of the $\mathrm{CsPb}_{2} \mathrm{Br}_{5}$. Detailed structural analysis on this material will be the subject of our future work.

\section{Conclusion}

In summary, the fast degradation of perovskites in the presence of water and moisture is a challenge for perovskite-based technologies and hinders the material's potential. In this work, we demonstrate that water can be a useful tool for the direct transformation of three-dimensional perovskites $\left(\mathrm{CsPbBr}_{3}\right)$ into the 2D PRM CsPb $\mathrm{Br}_{5}$. We revealed that our transformed 2D PRM film is a good green emissive optical medium exhibiting high thermal and environmental stabilities. The transformation occurs by a sequential dissolution-recrystallization process under the $\mathrm{PbBr}_{2}$ rich condition. We believe our finding is significant to perovskite technologies because it not only provides a new synthetic method to increase the moisture stability but also presents a vital strategy for obtaining highly emissive PRMs. The new developed water-induced direct transformation method will have an impact on the stabilization of PRMs for light-emitting applications.

\section{ASSOCIATED CONTENT}


Supporting Information. TD-XRD, SEM images, TEM images, PLQY, excitation wavelength dependent $\mathrm{PL}$ intensity, $\mathrm{XRD}$ of $\mathrm{CsPb}_{2} \mathrm{Br}_{5}$ with different ratio of chloride are included in Supporting Information.

\section{AUTHOR INFORMATION}

\section{Corresponding Authors}

*chon7@sch.ac.kr

*osman.bakr@kaust.edu.sa

\section{Author Contributions}

The manuscript was written through contributions of all authors. All authors have approved the final version of the manuscript.

\section{Notes}

The authors declare no competing financial interest.

\section{ACKNOWLEDGMENT}

The authors wish to thank to Abdullah S. Abbas for the help in the video editing. The authors acknowledge the funding support from King Abdullah University of Science and Technology (KAUST). This work was also supported by the Soonchunhyang University Research Fund.

\section{References}

1. Kojima, A.; Teshima, K.; Shirai, Y.; Miyasaka, T. Organometal halide perovskites as visible-light sensitizers for photovoltaic cells. J. Am. Chem. Soc. 2009, 131, 6050-6051.

2. Docampo, P.; Ball, J. M.; Darwich, M.; Eperon, G. E.; Snaith, H. J. Efficient organometal trihalide perovskite planar-heterojunction solar cells on flexible polymer substrates. Nat. Commun. 2013, 4, 2761.

3. Im, J.-H.; Lee, C.-R.; Lee, J.-W.; Park, S.-W.; Park, N.-G. 6.5\% efficient perovskite quantum-dot-sensitized solar cell. Nanoscale 2011, 3, 4088-4093. 
4. $\quad$ Kim, H.-S.; Mora-Sero, I.; Gonzalez-Pedro, V.; Fabregat-Santiago, F.; Juarez-Perez, E. J.; Park, N.-G.; Bisquert, J. Mechanism of carrier accumulation in perovskite thin-absorber solar cells. Nat. Commun. 2013, 4, 2242.

5. Christians, J. A.; Fung, R. C.; Kamat, P. V. An inorganic hole conductor for organo-lead halide perovskite solar cells. Improved hole conductivity with copper iodide. J. Am. Chem. Soc. 2013, 136, 758-764.

6. $\quad$ Kim, H.-S.; Lee, C.-R.; Im, J.-H.; Lee, K.-B.; Moehl, T.; Marchioro, A.; Moon, S.-J.; Humphry-Baker, R.; Yum, J.-H.; Moser, J. E.; et al. Lead iodide perovskite sensitized all-solidstate submicron thin film mesoscopic solar cell with efficiency exceeding 9\%. Sci. Rep. 2012, 2 , 591.

7. Akkerman, Q. A.; Gandini, M.; Di Stasio, F.; Rastogi, P.; Palazon, F.; Bertoni, G.; Ball, J. M.; Prato, M.; Petrozza, A.; Manna, L. Strongly emissive perovskite nanocrystal inks for highvoltage solar cells. Nat. Energy 2017, 2, 16194.

8. Tan, Z.-K.; Moghaddam, R. S.; Lai, M. L.; Docampo, P.; Higler, R.; Deschler, F.; Price, M.; Sadhanala, A.; Pazos, L. M.; Credgington, D.; et al. Bright light-emitting diodes based on organometal halide perovskite. Nat. Nanotech. 2014, 9, 687-692.

$9 . \quad$ Cho, H.; Jeong, S.-H.; Park, M.-H.; Kim, Y.-H.; Wolf, C.; Lee, C.-L.; Heo, J. H.; Sadhanala, A.; Myoung, N.; Yoo, S.; et al. Overcoming the electroluminescence efficiency limitations of perovskite light-emitting diodes. Science 2015, 350, 1222-1225.

10. Xing, G.; Mathews, N.; Lim, S. S.; Yantara, N.; Liu, X.; Sabba, D.; Grätzel, M.; Mhaisalkar, S.; Sum, T. C. Low-temperature solution-processed wavelength-tunable perovskites for lasing. Nat. Mater. 2014, 13, 476.

11. Dou, L.; Yang, Y. M.; You, J.; Hong, Z.; Chang, W.-H.; Li, G.; Yang, Y. Solutionprocessed hybrid perovskite photodetectors with high detectivity. Nat. Commun. 2014, 5, 5404. 12. Li, F.; Ma, C.; Wang, H.; Hu, W.; Yu, W.; Sheikh, A. D.; Wu, T. Ambipolar solutionprocessed hybrid perovskite phototransistors. Nat. Commun. 2015, 6, 8238.

13. Saidaminov, M. I.; Adinolfi, V.; Comin, R.; Abdelhady, A. L.; Peng, W.; Dursun, I.; Yuan, M.; Hoogland, S.; Sargent, E. H.; Bakr, O. M. Planar-integrated single-crystalline perovskite photodetectors. Nat. Commun. 2015, 6, 8724 .

14. Saidaminov, M. I.; Haque, M.; Savoie, M.; Abdelhady, A. L.; Cho, N.; Dursun, I.; Buttner, U.; Alarousu, E.; Wu, T.; Bakr, O. M. Perovskite photodetectors operating in both narrowband and broadband regimes. Adv. Mater. 2016, 28, 8144-8149.

15. Maculan, G.; Sheikh, A. D.; Abdelhady, A. L.; Saidaminov, M. I.; Haque, M. A.; Murali, B.; Alarousu, E.; Mohammed, O. F.; Wu, T.; Bakr, O. M. $\mathrm{CH}_{3} \mathrm{NH}_{3} \mathrm{PbCl}_{3}$ single crystals: Inverse temperature crystallization and visible-blind UV-photodetector. J. Phys. Chem. Lett. 2015, 6, 3781.

16. Cho, N.; Li, F.; Turedi, B.; Sinatra, L.; Sarmah, S. P.; Parida, M. R.; Saidaminov, M. I.; Murali, B.; Burlakov, V. M.; Goriely, A.; et al. Pure crystal orientation and anisotropic charge transport in large-area hybrid perovskite films. Nat. Commun. 2016, 7, 13407.

17. Bansode, U.; Ogale, S. On-axis pulsed laser deposition of hybrid perovskite films for solar cell and broadband photo-sensor applications. J. Appl. Phys. 2017, 121, 133107.

18. Chin, X. Y.; Cortecchia, D.; Yin, J.; Bruno, A.; Soci, C. Lead iodide perovskite lightemitting field-effect transistor. Nat. Comm. 2015, 6, 7383.

19. Kagan, C.; Mitzi, D.; Dimitrakopoulos, C. Organic-inorganic hybrid materials as semiconducting channels in thin-film field-effect transistors. Science 1999, 286, 945-947. 
20. Tathavadekar, M.; Krishnamurthy, S.; Banerjee, A.; Nagane, S.; Gawli, Y.; Suryawanshi, A.; Bhat, S.; Puthusseri, D.; Mohite, A. D.; Ogale, S. Low-dimensional hybrid perovskites as high performance anodes for alkali-ion batteries. J. Mater. Chem. A 2017, 5, 18634-18642. 21. Jeon, N. J.; Noh, J. H.; Kim, Y. C.; Yang, W. S.; Ryu, S.; Seok, S. I. Solvent engineering for high-performance inorganic-organic hybrid perovskite solar cells. Nat. Mater. 2014, 13, 897903.

22. Mitzi, D. B.; Wang, S.; Feild, C. A.; Chess, C. A.; Guloy, A. M. Conducting layered organic-inorganic halides containing $<110>$-oriented perovskite sheets. Science 1995, 267, 1473.

23. Nie, W.; Tsai, H.; Asadpour, R.; Blancon, J.-C.; Neukirch, A. J.; Gupta, G.; Crochet, J. J.; Chhowalla, M.; Tretiak, S.; Alam, M. A.; et al., High-efficiency solution-processed perovskite solar cells with millimeter-scale grains. Science 2015, 347, 522-525.

24. Grancini, G.; Marras, S.; Prato, M.; Giannini, C.; Quarti, C.; De Angelis, F.; De Bastiani, M.; Eperon, G. E.; Snaith, H. J.; Manna, L.; et al. The impact of the crystallization processes on the structural and optical properties of hybrid perovskite films for photovoltaics. J. Phys. Chem. Lett. 2014, 5, 3836-3842.

25. Abdelhady, A. L.; Saidaminov, M. I.; Murali, B.; Adinolfi, V.; Voznyy, O.; Katsiev, K.; Alarousu, E.; Comin, R.; Dursun, I.; Sinatra, L.; et al. Heterovalent dopant incorporation for bandgap and type engineering of perovskite crystals. J. Phys. Chem. Lett. 2016, 7, 295-301. 26. Saidaminov, M. I.; Mohammed, O. F.; Bakr, O. M. Low-dimensional-networked metal halide perovskites: The next big thing. ACS Energy Lett. 2017, 2, 889-896.

27. Murali, B.; Yengel, E.; Yang, C.; Peng, W.; Alarousu, E.; Bakr, O. M.; Mohammed, O. F. The surface of hybrid perovskite crystals: A boon or bane. ACS Energy Lett. 2017, 2, 846-856. 28. Seth, S.; Samanta, A., Photoluminescence of zero-dimensional perovskites and perovskite-related materials. J. Phys. Chem. Lett. 2017, 9, 176-183.

29. Seth, S.; Samanta, A. Fluorescent phase-pure zero-dimensional perovskite-related $\mathrm{Cs}_{4} \mathrm{PbBr}_{6}$ microdisks: Synthesis and single-particle imaging study. J. Phys. Chem. Lett. 2017, 8, 4461-4467.

30. Cha, J.-H.; Han, J. H.; Yin, W.; Park, C.; Park, Y.; Ahn, T. K.; Cho, J. H.; Jung, D.-Y. Photoresponse of $\mathrm{CsPbBr}_{3}$ and $\mathrm{Cs}_{4} \mathrm{PbBr}_{6}$ perovskite single crystals. J. Phys. Chem. Lett. 2017, 8, 565-570.

31. Zhang, L.; Sit, P. H.-L. Ab initio study of interaction of water, hydroxyl radicals, and hydroxide ions with $\mathrm{CH}_{3} \mathrm{NH}_{3} \mathrm{PbI}_{3}$ and $\mathrm{CH}_{3} \mathrm{NH}_{3} \mathrm{PbBr}_{3}$ surfaces. J. Phys. Chem. C 2015, 119, 22370-22378.

32. Frost, J. M.; Butler, K. T.; Brivio, F.; Hendon, C. H.; Van Schilfgaarde, M.; Walsh, A. Atomistic origins of high-performance in hybrid halide perovskite solar cells. Nano Lett. 2014, 14, 2584-2590.

33. Tenuta, E.; Zheng, C.; Rubel, O. Thermodynamic origin of instability in hybrid halide perovskites. Sci. Rep. 2016, 6, 37654.

34. Kulbak, M.; Gupta, S.; Kedem, N.; Levine, I.; Bendikov, T.; Hodes, G.; Cahen, D. Cesium enhances long-term stability of lead bromide perovskite-based solar cells. J. Phys. Chem. Lett. 2015, 7, 167-172.

35. Protesescu, L.; Yakunin, S.; Bodnarchuk, M. I.; Krieg, F.; Caputo, R.; Hendon, C. H.; Yang, R. X.; Walsh, A.; Kovalenko, M. V. Nanocrystals of cesium lead halide perovskites $\left(\mathrm{CsPbX}_{3}, \mathrm{X}=\mathrm{Cl}, \mathrm{Br}\right.$, and $\left.\mathrm{I}\right)$ : Novel optoelectronic materials showing bright emission with wide color gamut. Nano Lett. 2015, 15, 3692. 
36. Akbali, B.; Topcu, G.; Guner, T.; Ozcan, M.; Demir, M. M.; Sahin, H. CsPbBr 3 perovskites: Theoretical and experimental investigation on water-assisted transition from nanowire formation to degradation. Phys. Rev. Materials 2018, 2, 034601.

37. de Mello, J. C.; Wittmann, H. F.; Friend, R. H. An improved experimental determination of external photoluminescence quantum efficiency. Adv. Mater. 1997, 9, 230-232.

38. Simmons, E. Diffuse reflectance spectroscopy: A comparison of the theories. Appl. Optics 1975, 14, 1380-1386.

39. Li, G.; Wang, H.; Zhu, Z.; Chang, Y.; Zhang, T.; Song, Z.; Jiang, Y. Shape and phase evolution from $\mathrm{CsPbBr}_{3}$ perovskite nanocubes to tetragonal $\mathrm{CsPb}_{2} \mathrm{Br}_{5}$ nanosheets with an indirect bandgap. Chem. Commun. 2016, 52, 11296-11299.

40. Dursun, I.; De Bastiani, M.; Turedi, B.; Alamer, B.; Shkurenko, A.; Yin, J.; El-Zohry, A. M.; Gereige, I.; Alsaggaf, A.; Mohammed, O. F.; et al. $\mathrm{CsPb}_{2} \mathrm{Br}_{5}$ single crystals: Synthesis and characterization. ChemSusChem 2017, 10, 3746-3749.

41. Herz, L. M. Charge-carrier dynamics in organic-inorganic metal halide perovskites. Annu. Rev. Phys. Chem. 2016, 67, 65-89.

42. Gaponenko, M. S.; Lutich, A. A.; Tolstik, N. A.; Onushchenko, A. A.; Malyarevich, A. M.; Petrov, E. P.; Yumashev, K. V. Temperature-dependent photoluminescence of PbS quantum dots in glass: Evidence of exciton state splitting and carrier trapping. Phys. Rev. B 2010, 82, 125320 .

43. Zhang, Y.; Saidaminov, M. I.; Dursun, I.; Yang, H.; Murali, B.; Alarousu, E.; Yengel, E.; Alshankiti, B. A.; Bakr, O. M.; Mohammed, O. F. Zero-dimensional $\mathrm{Cs}_{4} \mathrm{PbBr}_{6}$ perovskite nanocrystals. J. Phys. Chem. Lett. 2017, 8, 961-965.

44. Li, J.; Yuan, X.; Jing, P.; Li, J.; Wei, M.; Hua, J.; Zhao, J.; Tian, L. Temperaturedependent photoluminescence of inorganic perovskite nanocrystal films. RSC Adv. 2016, 6, 78311-78316.

45. Shi, Z.; Li, S.; Li, Y.; Ji, H.; Li, X.; Wu, D.; Xu, T.; Chen, Y.; Tian, Y.; Zhang, Y.; et al. Strategy of solution-processed all-inorganic heterostructure for humidity/temperature-stable perovskite quantum dot light-emitting diodes. ACS Nano 2018, 12, 1462-1472

46. Shinde, A.; Gahlaut, R.; Mahamuni, S. Low-temperature photoluminescence studies of $\mathrm{CsPbBr}_{3}$ quantum dots. J. Phys. Chem. C 2017, 121, 14872-14878.

47. Wang, K. H.; Wu, L.; Li, L.; Yao, H. B.; Qian, H. S.; Yu, S. H. Large-scale synthesis of highly luminescent perovskite-related $\mathrm{CsPb}_{2} \mathrm{Br}_{5}$ nanoplatelets and their fast anion exchange. Angew. Chem. Int. Ed 2016, 55, 8328-8332.

48. Tang, X.; Hu, Z.; Yuan, W.; Hu, W.; Shao, H.; Han, D.; Zheng, J.; Hao, J.; Zang, Z.; Du, J.; et al. Perovskite $\mathrm{CsPb}_{2} \mathrm{Br}_{5}$ microplate laser with enhanced stability and tunable properties. Adv. Opt. Mater. 2017, 5, 1600788.

49. De Bastiani, M.; Dursun, I.; Zhang, Y.; Alshankiti, B. A.; Miao, X.-H.; Yin, J.; Yengel, E.; Alarousu, E.; Turedi, B.; Almutlaq, J. M.; et al. Inside perovskites: Quantum luminescence from bulk $\mathrm{Cs}_{4} \mathrm{PbBr}_{6}$ single crystals. Chem. Mater. 2017, 29, 7108-7113.

50. Guleria, A.; Neogy, S.; Maurya, D. K.; Adhikari, S. Blue light-emitting Si quantum dots with mesoporous and amorphous features: Origin of photoluminescence and potential Applications. J. Phys. Chem. C 2017, 121, 24302-24316.

51. Yang, S.; Li, W.; Cao, B.; Zeng, H.; Cai, W. Origin of blue emission from silicon nanoparticles: Direct transition and interface recombination. J. Phys. Chem. C 2011, 115, 2105621062. 
52. Yang, H.; Zhang, Y.; Pan, J.; Yin, J.; Bakr, O. M.; Mohammed, O. F. Room-temperature engineering of all-inorganic perovskite nanocrsytals with different dimensionalities. Chem.

Mater. 2017, 29, 8978-8982.

53. Zhang, Y.; Sinatra, L.; Alarousu, E.; Yin, J.; El-Zohry, A. M.; Bakr, O. M.; Mohammed, O. F. Ligand-free nanocrystals of highly emissive $\mathrm{Cs}_{4} \mathrm{PbBr}_{6}$ perovskite. J. Phys. Chem. C 2018, DOI: $10.1021 /$ acs.jpcc.8b01735.

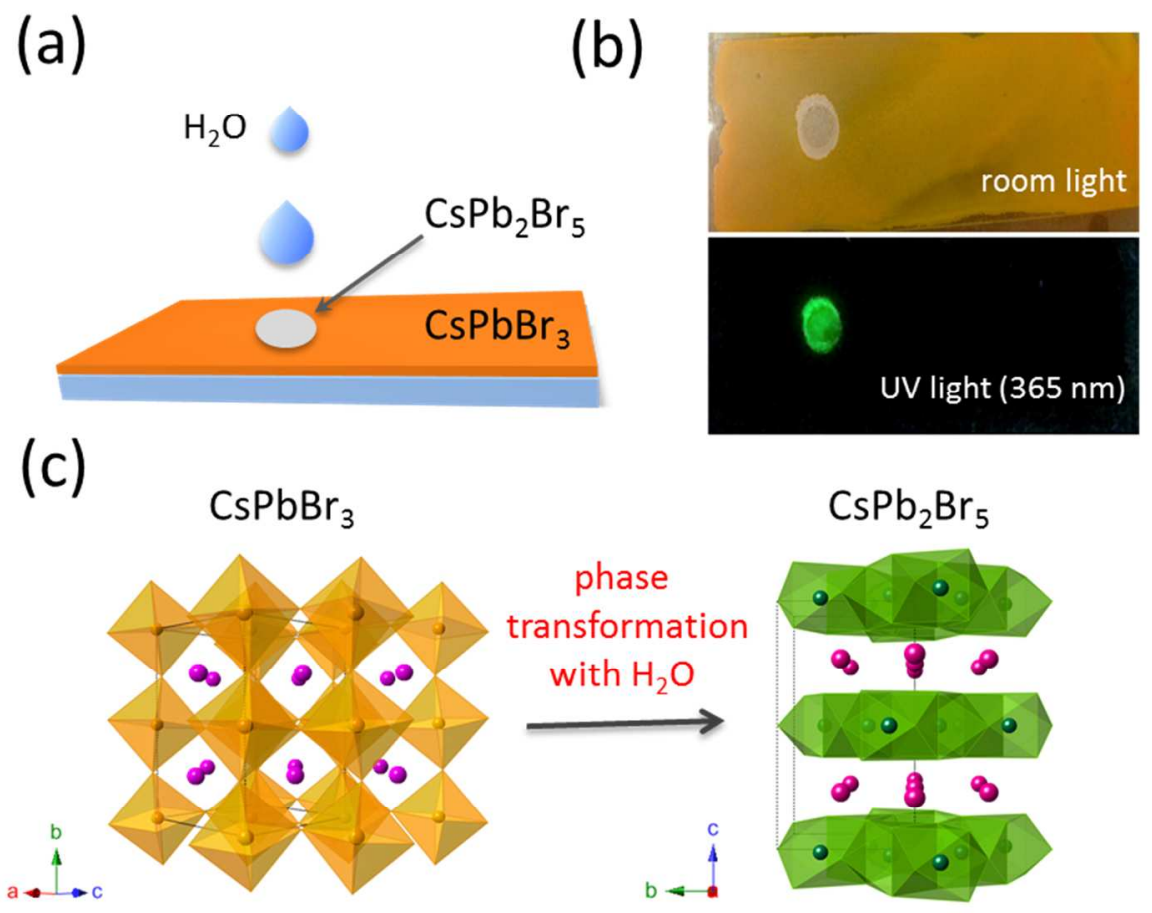

Figure 1. (a) Schematic representation of the water induced direct transformation of $\mathrm{CsPbBr}_{3}$ to $\mathrm{CsPb}_{2} \mathrm{Br}_{5}$. (b) Photographic image of water treated films under room light and $\mathrm{UV}$ light. (c) The structure of cubic $\mathrm{CsPbBr}_{3}$ and tetragonal $\mathrm{CsPb}_{2} \mathrm{Br}_{5}$. 


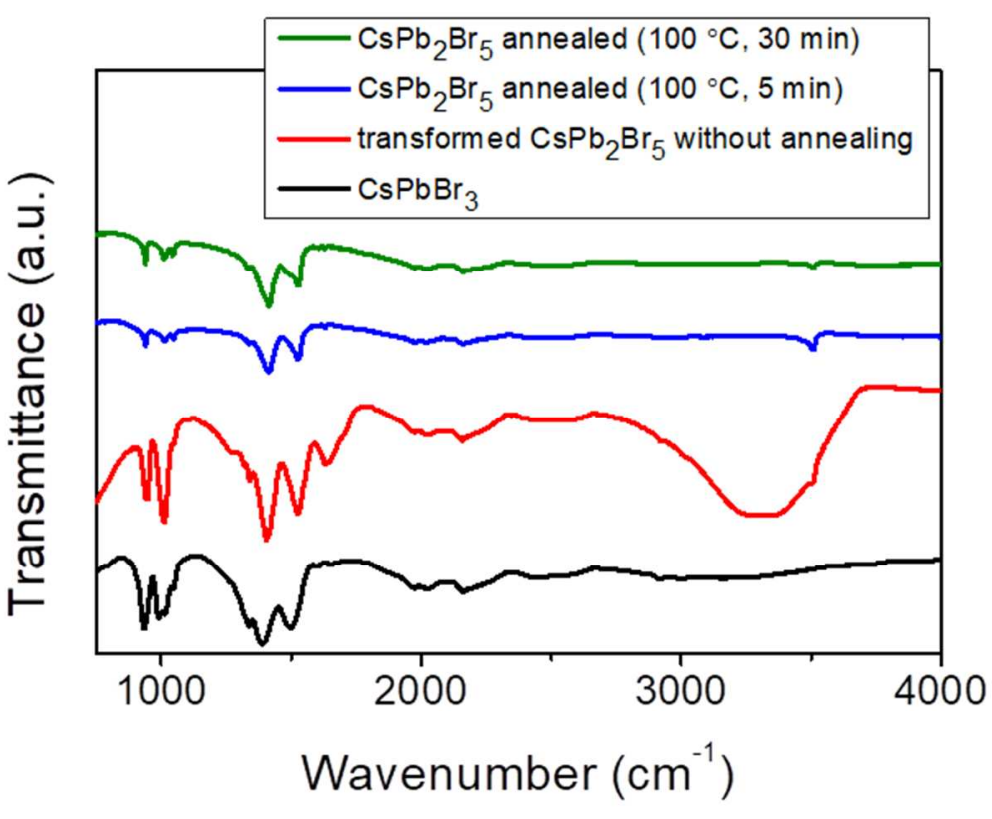

Figure 2. FT-IR spectra of $\mathrm{CsPbBr}_{3}$, the transformed $\mathrm{CsPb}_{2} \mathrm{Br}_{5}$ before and after annealing for $5 \mathrm{~min}$ and $30 \mathrm{~min}$ at $100^{\circ} \mathrm{C}$. The broad water peak (red line) observed from 3000 to $3600 \mathrm{~cm}^{-1}$ was disappeared after thermal annealing. 


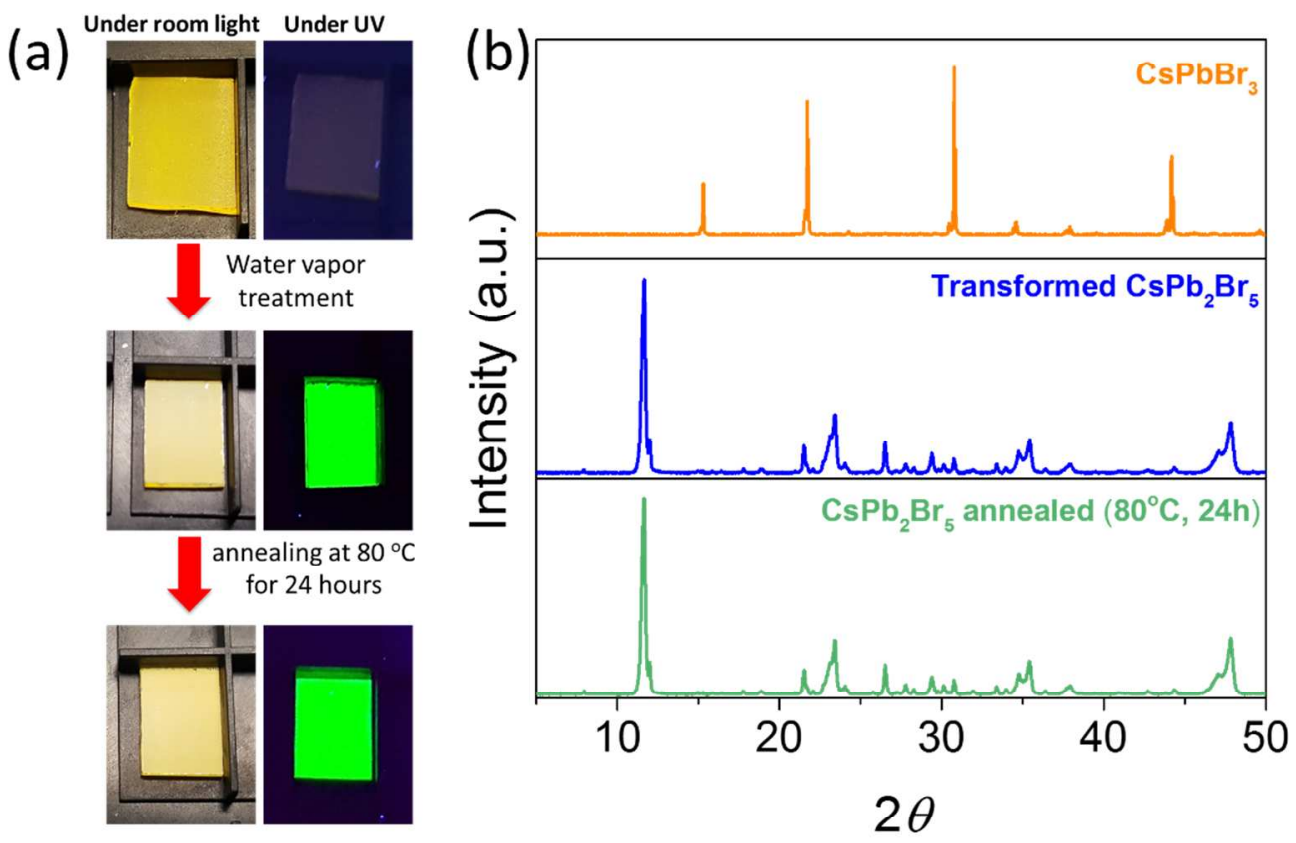

Figure 3. (a) Photographic images of $\mathrm{CsPbBr}_{3}$ films after drop casting (top), transformation to $\mathrm{CsPb}_{2} \mathrm{Br}_{5}$ by water vapor treatment (middle), and annealing at $80{ }^{\circ} \mathrm{C}$ for $24 \mathrm{~h}$ (bottom). (b) $\mathrm{XRD}$ of $\mathrm{CsPbBr}_{3}$ (before transformation), the transformed $\mathrm{CsPb}_{2} \mathrm{Br}_{5}$ film and after annealing $80^{\circ} \mathrm{C}$ for $24 \mathrm{~h}$. 
(a)

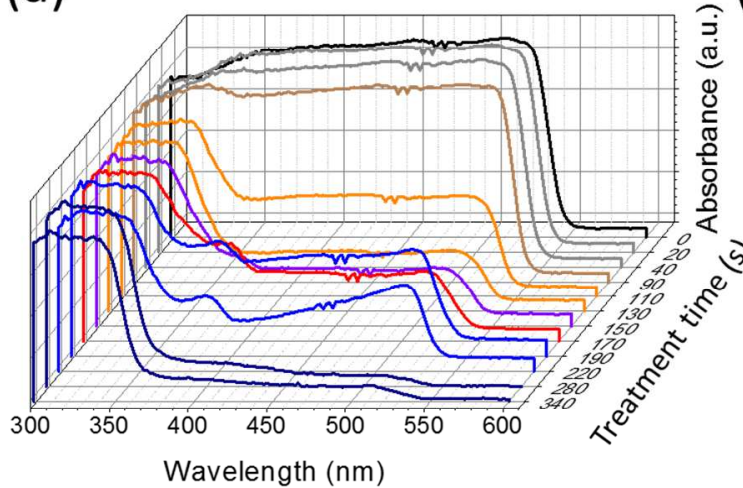

(c)

(b)

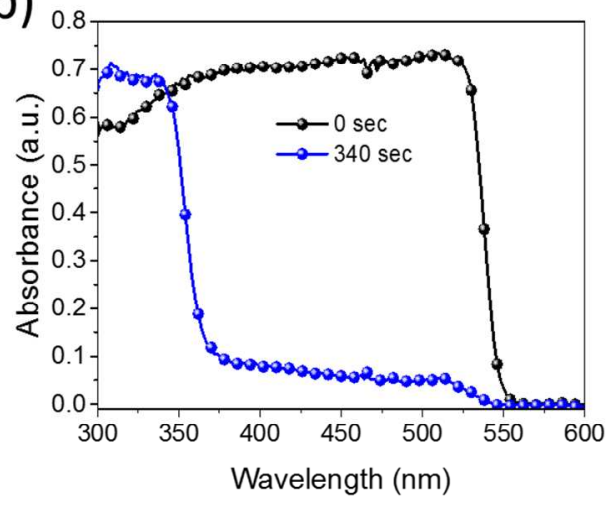

(d)

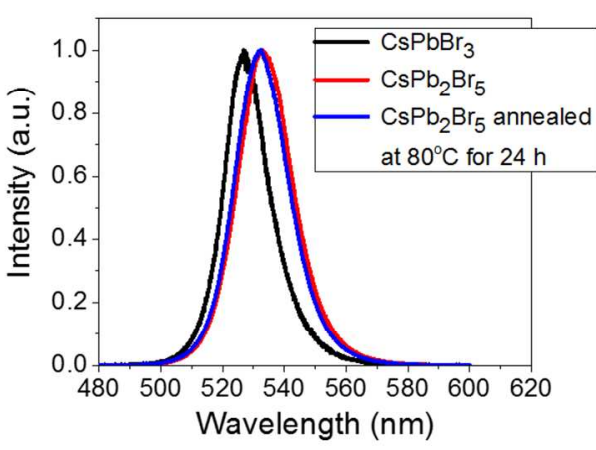

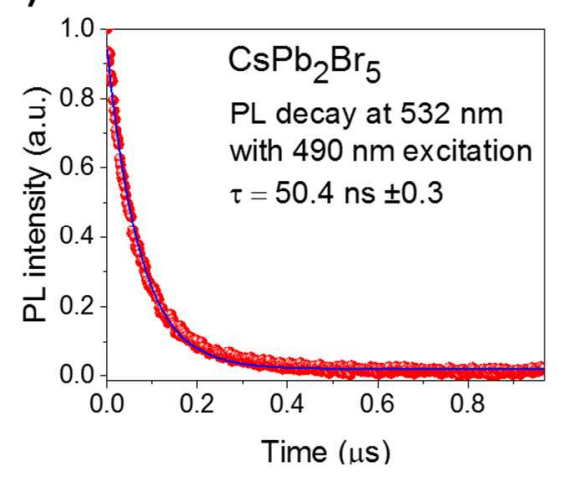

Figure 4. (a) The evolution of absorption spectra depending on the exposure time of $\mathrm{CsPbBr}_{3}$ films on water vapor. (b) The absorption spectra of $\mathrm{CsPbBr}_{3}$ film before and after water vapor treatment for 340 sec. (c) $\mathrm{PL}$ spectra of $\mathrm{CsPbBr}_{3}$, transformed $\mathrm{CsPb}_{2} \mathrm{Br}_{5}$, and after annealing for $24 \mathrm{~h}$ at $80{ }^{\circ} \mathrm{C}$ in air. (d) Time-resolved PL spectrum of the transformed $\mathrm{CsPb}_{2} \mathrm{Br}_{5}$ film with an excitation wavelength of $490 \mathrm{~nm}$. 
(a)

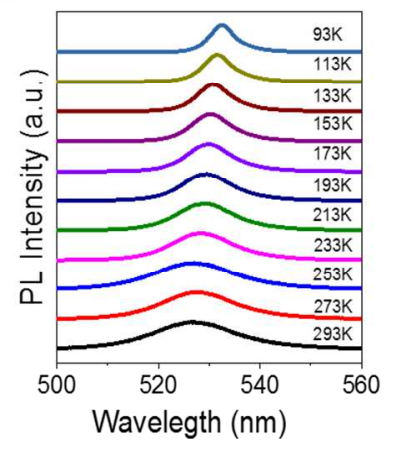

(b)

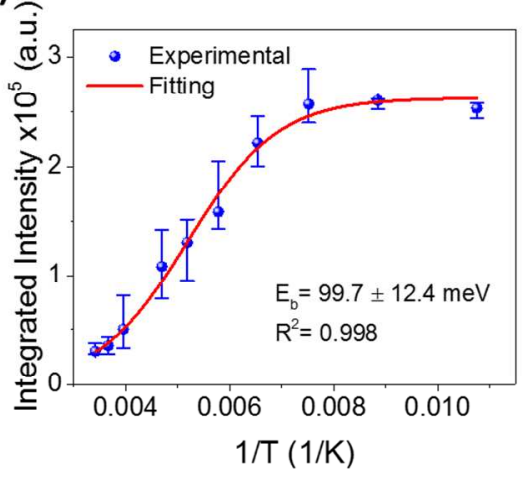

(c)

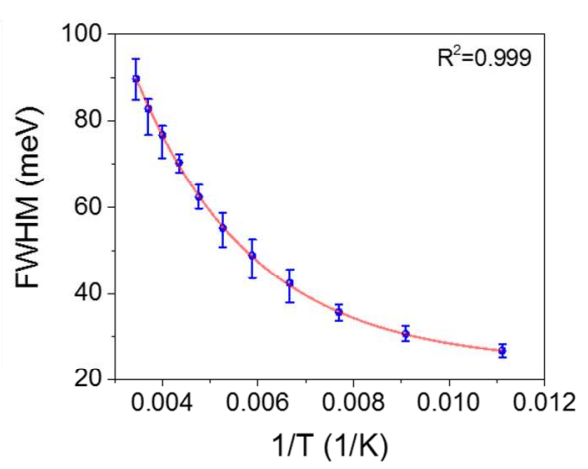

Figure 5. (a) Temperature-dependent $\mathrm{PL}$ spectra of transformed $\mathrm{CsPb}_{2} \mathrm{Br}_{5}$ in the range of 93-293 ${ }^{\circ} \mathrm{K}$. (b) The integrated PL intensity and (c) full-width and half maxima (FWHM) versus temperature.

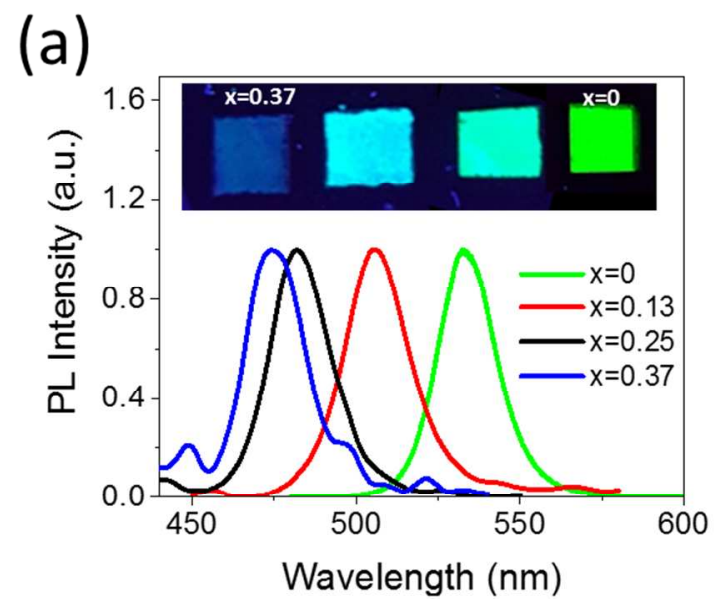

(b)

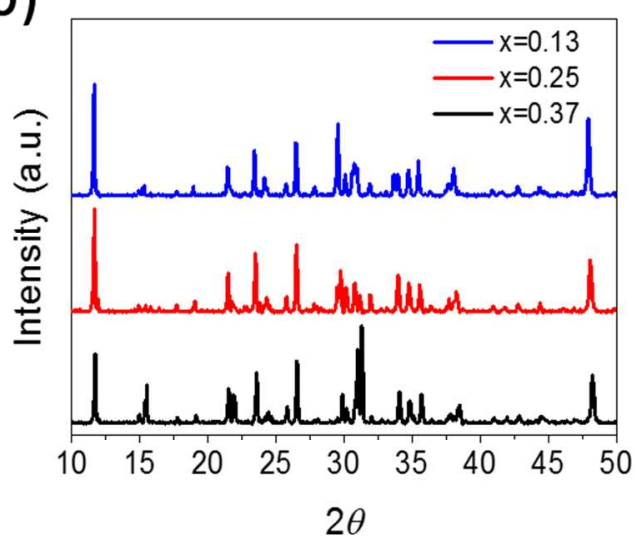

Figure 6. (a) $\mathrm{PL}$ spectra of $\mathrm{CsPb}_{2} \mathrm{Br}_{5(1-x)} \mathrm{Cl}_{5 x}$ films. Inset shows the photographic image of transformed films under UV irradiation. (b) XRD of $\mathrm{CsPb}_{2} \mathrm{Br}_{5(1-\mathrm{x})} \mathrm{Cl}_{5 \mathrm{x}}$ films with different ratio of chloride. 
TOC Graphic

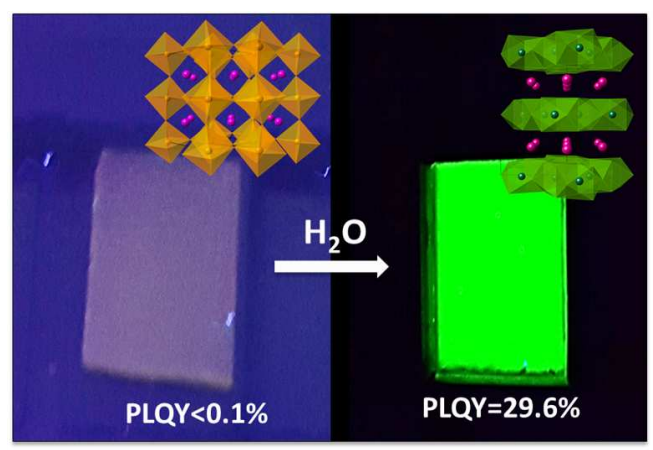

